\title{
Testing M-Payment for Utilities in Saudi Arabia Barriers and Opportunities for E-Government
}

\author{
Anan Alssbaiheen, Brunel University, UK \\ Steve Love, The Glasgow School of Art, UK
}

\begin{abstract}
This paper explored the opportunities and challenges facing e-government in Saudi Arabia. A prototype mobile phone application for paying different utilities was developed. The respondents were asked to use and evaluate the application. The results revealed that application was user friendly and useful for the users. However, the results showed that respondents showed concern over the security issues and declined to use any untrusted method of payment, displaying a lack of trust in online payment methods.
\end{abstract}

\section{KEYWORDS}

Challenges, Customization of Services, E-Government, Mobile Government, Opportunities

\section{INTRODUCTION}

Alotaibi and Roussinov (2015) described that E-government enables governments to provide better services to the public and to enhance their efficiency in interaction among themselves, businesses and government agencies. The Government of Saudi Arabia has attached significant importance to E-government and its implementation to improve service provision in the country, with the pioneering 'Yesser' ('simplify') program (Palas, Uddin and Hassan, 2019) relating to procedures, legislations and activities related to E-government implementation. This supports the fact that the government understands that significance and potential of Information and Communications Technology (ICT) to make operations easier and simpler. This service facilitates interaction between the users and agencies and also among agencies as well. In order to provide better, reliable and competitive services to citizens, governments across the world, especially in Middle East are taking advantage of technology and changing their traditional procedures (Alrowili, Alotaibi and Alharbi, 2015).

However, there are many complexities involved in the provision of M-government services analogous to E-commerce; many users cannot find the exact product they aim to buy and also find online buying procedures complex and difficult, thus limiting impulse purchase online (Alonazi, Beloff and White, 2019; Mainka, Hartmann, Meschede, and Stock, 2015). Consumer trust is one of the important factors that has a huge impact on their behaviour and attitude towards products and servicesthey aim to use. According to different scholars, trust refers to the 'willingness of one party to take risk and be part of other party actions based on their expectation and having little or no control over others action' (Almaimoni, et al 2018). Individuals' buying decisionsare based on their trust levels in certain products or services. Moreover, online trust is essential for building longterm relations with customers, but the trust level in online interactions is lower than in face-to-face traditional formats (Alotaibi and Roussinov, 2015).

\section{DOI: 10.4018/IJORIS.20210401.oa4}

This article, published as an Open Access article on March 26th, 2021 in the gold Open Access journal, the International Journal of Operations Research and Information Systems (converted to gold Open Access January 1st, 2021), is distributed under the terms of the Creative Commons Attribution License (http://creativecommons.org/licenses/by/4.0/) which permits unrestricted use, distribution, and production in any medium, provided the author of the original work and original publication source are properly credited. 
There is a direct positive relationship between electronic service and trustworthiness and privacy security provided by the companies (Sultana, Ahlan, and Habibullah, 2016). High technical competence highly influences the trustworthiness of individuals (Saxena, 2017). There are multiple factors faced by the country that slow the growth of E-government (Kanaan, Abumatar, Al-Lozi, and Hussein, 2019). Most factors include difficulty in bank transactions, transfer of payments and finally the access and speed of internet. Furthermore, unclear regulations, lack of trust and under- developed after sale and customer services hampers online service. Despite of so many challenges, there are many supportive drivers that exist in Saudi market which support growth of E-government and its effective adoption. There is strong support of government for ICT technologies; growing sector, favorable and strong foundation for E-government agencies (Nawafleh, 2018). This study will focus on to different challenges and opportunities mobile service provides to E-government in Saudi Arabia. Study will highlight the opportunities that exist in Saudi Arabia and how consumer behaviour has evolved over time to new change. Saudi Arabia is a country with high moral and values, so cultural issues will be highlighted that cause resistance to change and accept new methods of interaction. This research will explain the implementation and development of E-government through recent practises and highlights challenges that effects the implementation in effective manner. The main aim, objectives and research question have been shown below.

The main aim and purpose of this research is to better understand the challenges and opportunities that mobile service creates for E-government in Saudi Arabia, and how these challenges and opportunities impact on citizens. This paper aims to address challenges and behavioural impact on citizens and to explore the effective implementation of E-government. Thus the research objectives are to explore the following dimensions in the context of Saudi Arabia:

- To investigate the key aspects of E-government;

- To study the challenges associated with use of mobile technology in E-government;

- To investigate how these challenges impact the user experience of E-government through mobile service;

- To understand how consumer behaviour is affected due to E-government challenges.

\section{LITERATURE REVIEW}

\section{E-Government in Saudi Arabia}

In 1998, the first national E-government initiative began in Saudi Arabia (Baabdullah, Alalwan, and Al Qadi, 2018). According to various authors, most of the challenges faced during adoption and implementation of E-government are linked to service provider and users (Santa, MacDonald, and Ferrer, 2019). Adoption and implementation of E-government provide numerous advantages to government, business and citizens. E-government helps its user to have access to its government service 24/7 (Arias, and Maçada, 2018). From an individual point of view, they are more concerned to accessibility of government than quality of the service.For effective implementation service providers need to make sure that the time is not an issue. The population size of Saudi Arabia fully supports the implementation and success of E-government (Al-Khatib, Lee, Suh, and Weerakkody, 2019). The availability of E-government minimizes the issue of physical distance between government agencies and citizens (Ciesielska, and Janowski, 2019). Through the use of mobile service, emails and video conferencing the cost of interaction among government agencies has reduced significantly (Valle-Cruz, 2019). E-government helps to achieve transparency of operation in public sector, by providing huge amount of information which was not possible in the past, reducing conceptual as well as logistical barriers between citizens and government (e-government service users and providers) (López-López, Iglesias-Antelo, Vázquez-Sanmartín, Connolly, and Bannister, 2018). 


\section{Challenges of E-government in Saudi Arabia}

There are many internal and external challenges linked to adoption and implementation of E-government in Saudi Arabia. According to researchers like Thompson, Mullins, and Chongsutakawewong, (2019); Liu, and Ma, (2019), the major concern highlighted during implementation of E-government is the security and privacy of data. One of the important concerns during the implementation of E-government is the availability of proper infrastructure for effective implementation in developing countries. Other challenges include issues like trust, lack of accountability, authentication, and availability of expertise during development and later the time of usage (Ali, Mazen, and Hassanein, 2018; Mahmood, 2019). Providing E-government service through different platforms like mobile service, internet, TV, or devices is major issue faced in developing countries, particularly Saudi Arabia where people experience significant problems in banking transactions, which is key determinant for the growth of E-government activities among users, especially through use of mobile services. Current agencies that regulate online money transactions do not have effective organizational and network structure to support payment transactions, which limits business activities that involve E-government (Joshi, Islam, and Islam, 2017).

Such facilities have key determinants for gaining consumers' trust and generating a sense of security in using online banking facilities. Better online facilities motivate consumers to practice online purchase of goods and services (Lallmahomed, Lallmahomed, and Lallmahomed, 2017). According to Pradhan, and Shakya, (2018), slow and unreliable speed of broadband connection is one of the main hindrances to the usage of E-government in Saudi Arabia. Association among the stakeholders and citizens should be prioritized and is known as a crucial aspect in improvement of E-government that enables efficient implementation and transformation of services (Isagah and Wimme, 2017). However, focus and development of use of mobile service as a platform for E-government will not only revitalize the public sector by improving the interaction and communication among the government agencies and citizens but also provide opportunities for economic growth, job creation and encourage technological advancement. Saudi Arabia needs to develop strategies that encourage growth of efficient implementation of E-government through various platforms, which will further lead to foreign investment and expertise that will help achieve growth and business competency (Alenezi, Tarhini, and Masa'deh, 2015).

\section{Impact of Culture on Behaviour of Citizens of Saudi Arabia}

National culture effects behaviour of a society as a whole and also at an individual level.Resistance towards change varies from culture to culture. Some cultures are known to have traditional behaviour, as they are slow to accept change and their level of resistance is high (Albugami, and Ahmed, 2015; Franklin, and Aguenza, 2016), while others are generally open to change; some cultures will oppose any attempts at change with complete resistance (Khazma, Al-Najjar, and Steinberg, 2016). This research also relates change to time-orientation, which to a large extent influences people's behaviour regarding change (Robertson, Al-Khatib, and Rasheed, 2013). Saudi Arabia is a generally conservative culture in terms of social interactions, but it has tremendous openness to technological innovation when analysed and accepted in light of previous principles, traditions and contexts (Almaimoni, et al 2018). Some cultures are known to be present oriented, living in the moment. For these types of societies history is not that relevant and future is never the main concern. However, there are societies which only focus only on the future. Their prime focus is on the development and setting targets for future growth and prosperity. The countries of the Gulf Cooperation Council (GCC), including Saudi Arabia, represent a blend of traditional, present, and future oriented approaches in many respects as they struggle to preserve their traditional identity while racing to modernise their countries and economies for a global economy and post-oil world (Scott-Jackson, and Michie, 2017).

As Oreg, and Sverdlik, (2018), suggested, resistance to change is often due to fear of altering the traditional way of doing things, repetitive habit, lack of resources, threat to authority and power, fear of unknown results are the reasons behind more resistance towards change in all the societies. 
Different researches highlight different reasons behind resistance for change (Oreg, and Sverdlik, 2018). Some suggest that social, personal economical factor influence resistance, while other suggests vague relation between personal and organizational goals. The traditional aspects of Saudi Arabia linked to change resistance pertaining to online transactions in particular are due to the unpredictable results that the change can bring. Resistance to change can be explained as negative reaction that individual shows towards change, as they believe that change is against their personal interest and objectives. Resistance is a form of protection that individual applies to their actual or assumed fear of change that might affect their personal interest. Resistance can be in different forms and type. Change is known as essential factor in towards world due to increased competition, globalization, and environmental change (Dereli, 2015; Cleveland, Rojas-Méndez, Laroche, and Papadopoulos, 2016).

\section{Existing Gap in Literature}

There is need to understand the usefulness and challenges that mobile service created for E-government in Saudi Arabia, a consumer-oriented societywith a lifestyle that is more focused towards consumption, which is a relatively new cultural trend. This literature study helps as an addition to existing academic literature on the industry of E-government that exists in Saudi Arabia, focusing on the challenges that it faces, how consumer behaviour is influenced and what opportunities exist in the country for mobile service providers. Most of the existing research is focused on challenges of E-government faced alone and ignored the quality of service provided for mobile service and how it has contributed to overall operation of E-government. Therefore, this research aims to fill this gap in the literature.

\section{RESEARCH METHODOLOGY}

\section{Research Strategy and Design}

Initially, primary data is collected using "thinking aloud" technique (Ericsson and (Walliman, 2017). In this method, respondents are asked to think aloud while thinking about solving a problem or making a decision. This enables the researchers to observe the task-completion process first-hand instead of looking at the final outcome. Researchers are expected to take notes of the verbal behaviour of the respondents without trying to interpret words and actions. The sessions were video and audio recorded. The aim of this method was to create explicit reports of the implicit processes and practices involved in the actual practice and performance of a task.

Thinking aloud method is based on the assumption that human brain works like an automated information processing system which involves "a memory containing symbol structures, a processor, effectors and receptors" (Kumar, 2017; Morente-Molinera, Pérez, Ureña and Herrera-Viedma, 2015). Börnert, and Wilbert, (2015) suggest that human memory has to distinct memories, short- and longterm. Short-term memory contains information that is instantly available to be used by the problem solver, but it is temporary and has limited application beyond particular situations Cowan (2017). On the other hand, long-term memory is stored in a large number of integrated nodes. To use long-term memory, it needs to be converted into short-term memory.10-15 randomly selected respondents were observed for this purpose. This facilitated the understanding of the users' mental model about the design and the use of mobile phone application along with understanding any issues they foresee in the use of this application.

This thinking aloud method was followed by the use of a qualitative research design to generate in-depth data about the willingness of the people to use this service, their concerns of safety and security and the overall process of making payments. Data was collected using semi-structured, face-to-face interviews, which initially asked questions about each of the above steps involved in the bill payments using mobiles. The participants were presented the complete Microsoft Visio drawn prototype on paper and the purpose was explained (Davis, Hsiao, Popova and Magerko, 2015). 


\section{Research Purpose}

The research purpose was to understand what the respondents think about the payment of utility bills using mobile phones. This helped to receive feedback from the respondents as well as understand the willingness of the respondents to use this service on their mobile phones. This study also provides data about any concerns of the users about the use of this service including the ease of use, any security concerns they have about their personal and credit or debit cards information or any other issues relevant to paying bills through mobile. In other words, this prototype study brings to the fore opportunities and challenges of the mobile government services particularly utility bills services using online system.

\section{Sample Size and Data Collection}

A small-scale study with 15 participants (9 male and 6 female), aged between 18-50 years was carried out. Data was collected using semi-structured interviews, which asked questions about the use different steps involved in the bill payments using mobiles. The participants were to explain the purpose through testing prototype design and features in order to improve the features and make it easier for the users. After the test, people were asked questions about each different steps of the online payment system and main focus was to understand what kind of issues they face in every step. Questions were also asked about different any issues in order to understand the perceptions of the respondents about this overall service. The test was video recorded, they were informed about video recording, and permission was taken from them. According to Kelly, Dowling, and Millar, (2018), data is easily available to researchers by virtue of its position.

\section{Ethical Considerations}

Observing ethical considerations are one of the important concerns of research (Wallace, and Sheldon, 2015), or else it will raise questions for the validity and authenticity of the research that is being conducted.Participants were informed beforehand about all the pros and cons of being involved in research. They were given full liberty of whether to become part of this research or not. Respondents were allowed to withdraw from research whenever they feel that the process is violating their personal space and they were made aware of what is required of them well before time (Saunders, Lewis, Thornhill, and Bristow, 2015). They were assured of complete secrecy. Therefore, the whole research was carried out morally and ethically.

\section{ANALYSIS}

\section{Application Development}

Eclipse Classic Version was used to develop this prototype for pilot testing. Eclipse is used by millions of developers around the world. Moreover, Eclipse was developed by hundreds of expert developers to accommodate most common difficulties, especially when Android became one of the most powerful platforms. The application was designed using Eclipse platform using a Windows operating system platform. As soon as the development tool was downloaded along with its Android plugins, the development process started. The application was downloaded on an Android phone selected specially for the purpose of this study. The mobile handset chosen for the study was Samsung S5 with latest Android version.

\section{Task}

In this study, the M-government service enabled online payment of utility bills (electricity, water, phone and internet). At the beginning, the user taps on the application icon located at the home screen on the Android smart phone provided (see Figure 1). 
There are two buttons showing on the screen for language selection. By clicking or touching on any of these buttons, the users can select the language and this will take them to the next step (see Figure 2).

In this step, users will have to register themselves online. It is necessary for all the users that they register online to use this service. If they are not already registered, they will have to register first. Existing users can log on using their unique user name and password while new users can register using their full name and address, which prompts the system to generate available user names. A user can choose appropriate user name and set the password. For the already registered users, the screen shown in Figure 3 appears.

After successful login to the system, the screen shown in Figure 4 appears.

There is a main button of options, which provides them with the choice of which utility bill they want to see and pay. Underneath the options button, there are three other buttons showing the options of electricity, water and phone and internet. By checking the appropriate button and entering the reference in the reference space, the users, by clicking the view button, are able to see the amount of bills against their name for the particular service. The windows shown in Figure 5 open, providing updated information about the prices of the utilities.

After pressing the OK button, the windows shown in Figure 6 open.

Figure 1.

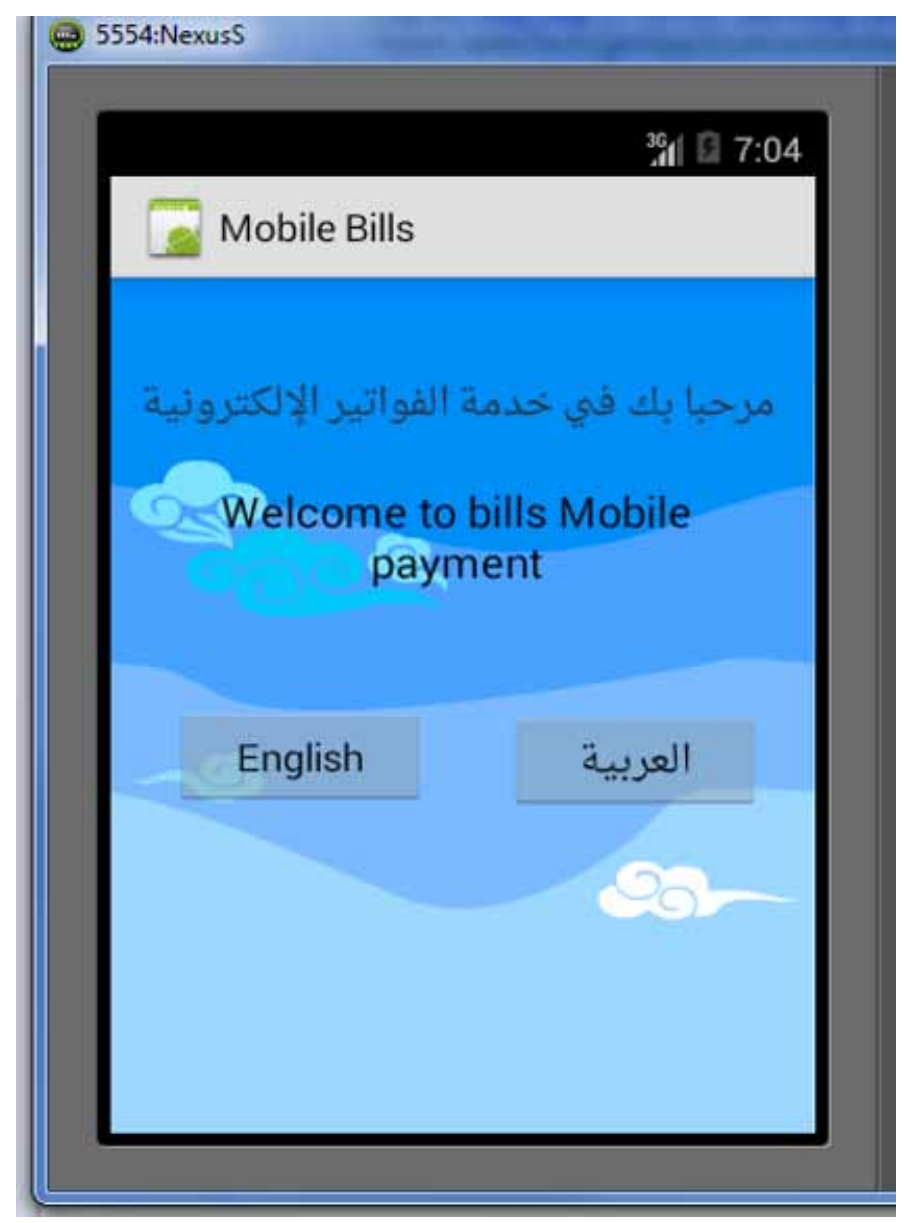


Figure 2.

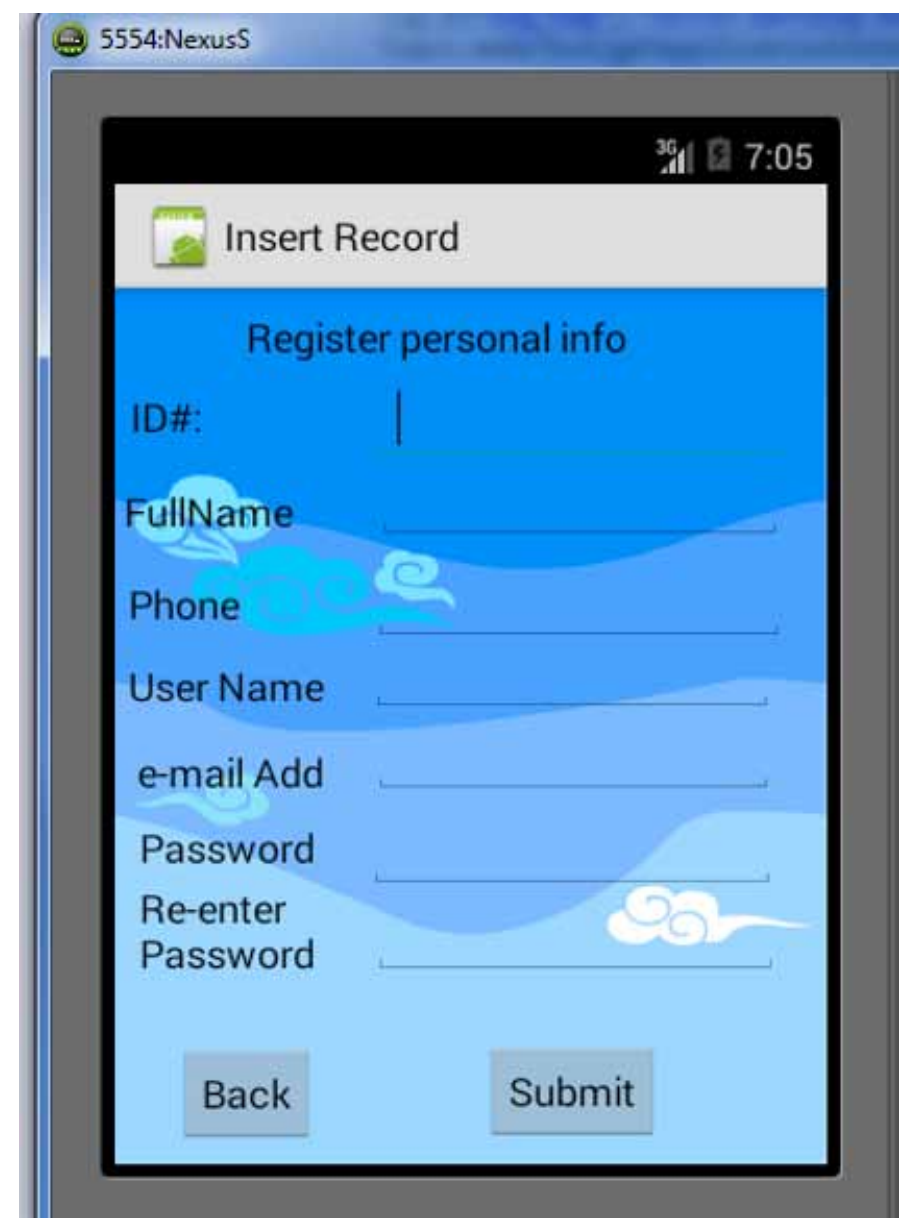

In case a user chose electricity service, the above-mentioned screen will show the number of bills against his/her name. The user can choose to view the detail of the bills by choosing the view button, which will take him/her to the next screen. However, the users can opt to go to main menu as well. By choosing to pay a particular bill, the user will see the screen shown in Figure 7.

This screen provides details of the bill, including the amount to be paid, the owner's name, address and period for which the bill is generated and due. The users have two different options on this screen: view the amount of the bill or go back. If they chose to view the bill, the screen shown in Figure 8 appears about making payment.

This screen is about making the payments. The users will have options of selecting the payment type such as visa or master card. By entering the card number, name, expiry date and security code, and then by choosing the "complete" button, the users will make the payment for the chosen service, which in this particular example was electricity. As the users press the complete button, the screen shown in Figure 9 about payment confirmation appears.

If the user presses the confirm button, the next screen which appears is about the license agreement. To complete the transaction, the user will also have to sign the agreement as shown in Figure 10.

After making the payment, the users will see the message shown in Figure 11.

The screen in Figure 11 has two buttons and they can close the application or opt to enter the main menu. This is the final step for paying the bills. 
Figure 3.

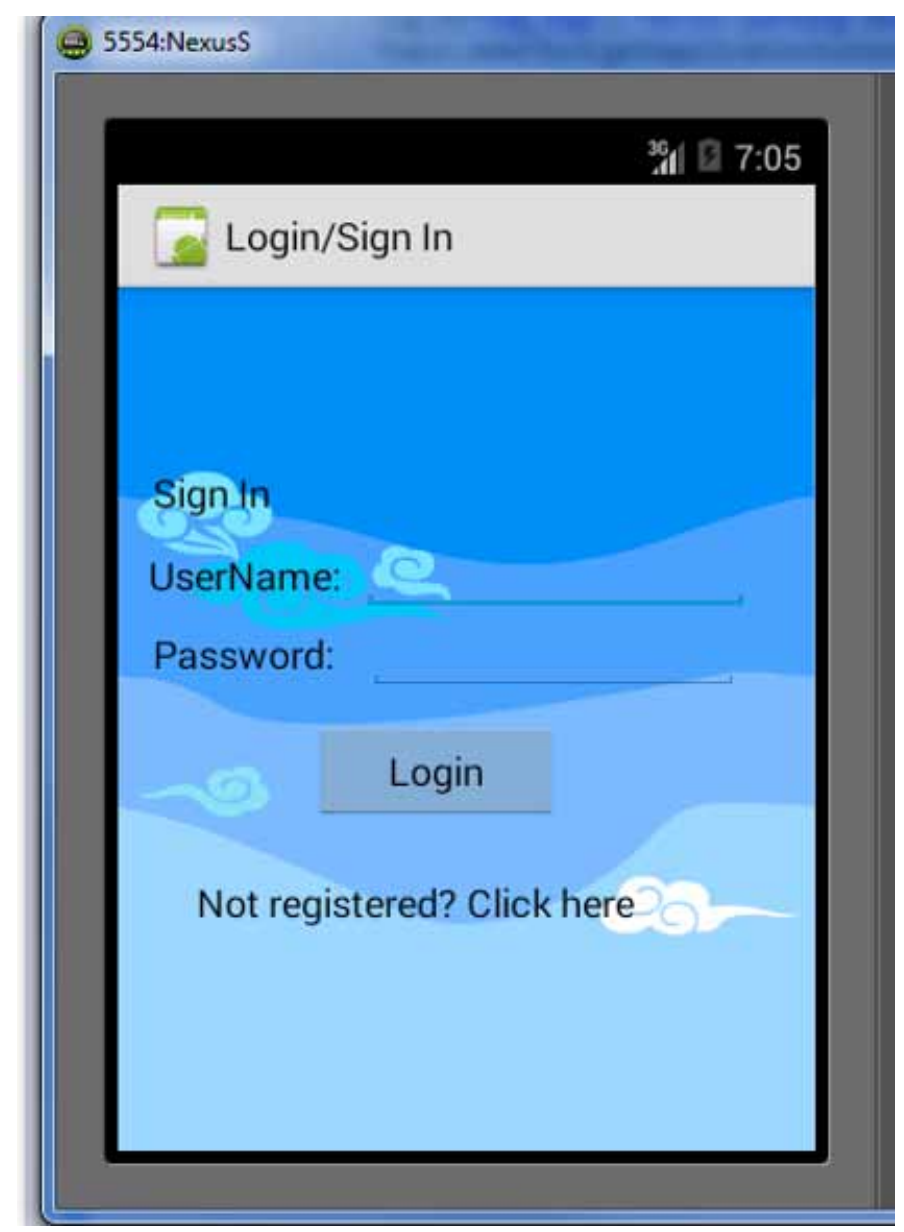

\section{Findings of the Pilot Study}

After the competition of the development, the data was collected from the participants using semistructured questions about both the usability of application and any other concerns regarding mobile bill payment, as the study is conducted on finding out the applicability or practicality of a mobile phone application for certain government services encompassing the user friendliness, purposeful, non-cumbersome nature and effectiveness of the service.

Participants' overall response towards this application was positive. They approve of the usability and easy of navigation of this application through mobile government services. Some of the main features that are liked by participants are its user-friendly approach, simplicity and effectiveness. Responding to the disliked features, most of the participants are content with using it, but some suggested improving the interface and physical appearance of the application. Almost $50 \%$ of participants ( 8 of 15) are not aware of availability of other mobile government services, and hence they were not using these services, but all of them expressed their intention to using mobile government services if provided.

Some of the participants expressed concern about the security of their personal data and information, but they mentioned that with a sound and reliable service provider, they are willing to use this service. Many participants are of the view that their personal information will not be misused, 
Figure 4.

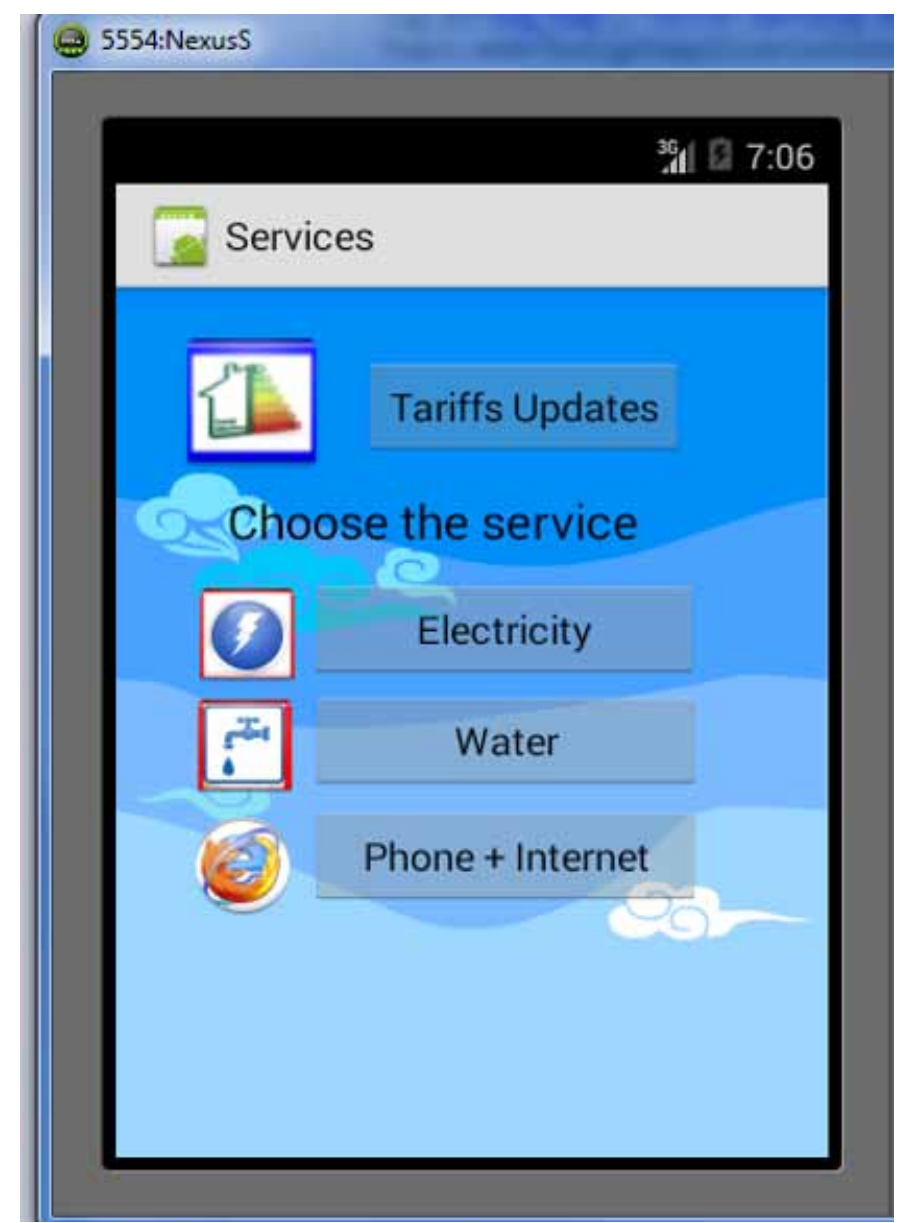

while a few remained highly concerned about this issue. Security, internet charges and people who are not good at using smart phones were tagged as challenges that is required to be surmount for the success of this application. This study also explains that speed, availability and internet charges are also concerns. There are places that are not yet properly covered by internet service providers, which hampered the use of this application.

Participants consider time-saving and convenience as the main positive attributes of this application and it provides access to government services with less effort. Keeping in view the current usage of mobiles, most of the respondents consider this idea as good option.

The results clearly speak indicate that the service is liked by the participants, with a few concerns about the security and reliability of services. These concerns can be addressed through better and experienced service provider with control over personal data. Though most of the participants showed trust in the proper use of their personal and financial data, some are indecisive. Strict laws and regulations are also required to win the trust of users and protect them from fraudulent activities.

Overall, this service is appreciated and respondents show willingness to use this service as it saves them going to bank for paying their bills against utilities. The obvious recommendations emergent from the study are the improvement of security and reliability features backed by a legally developed data protection framework. 
Figure 5.

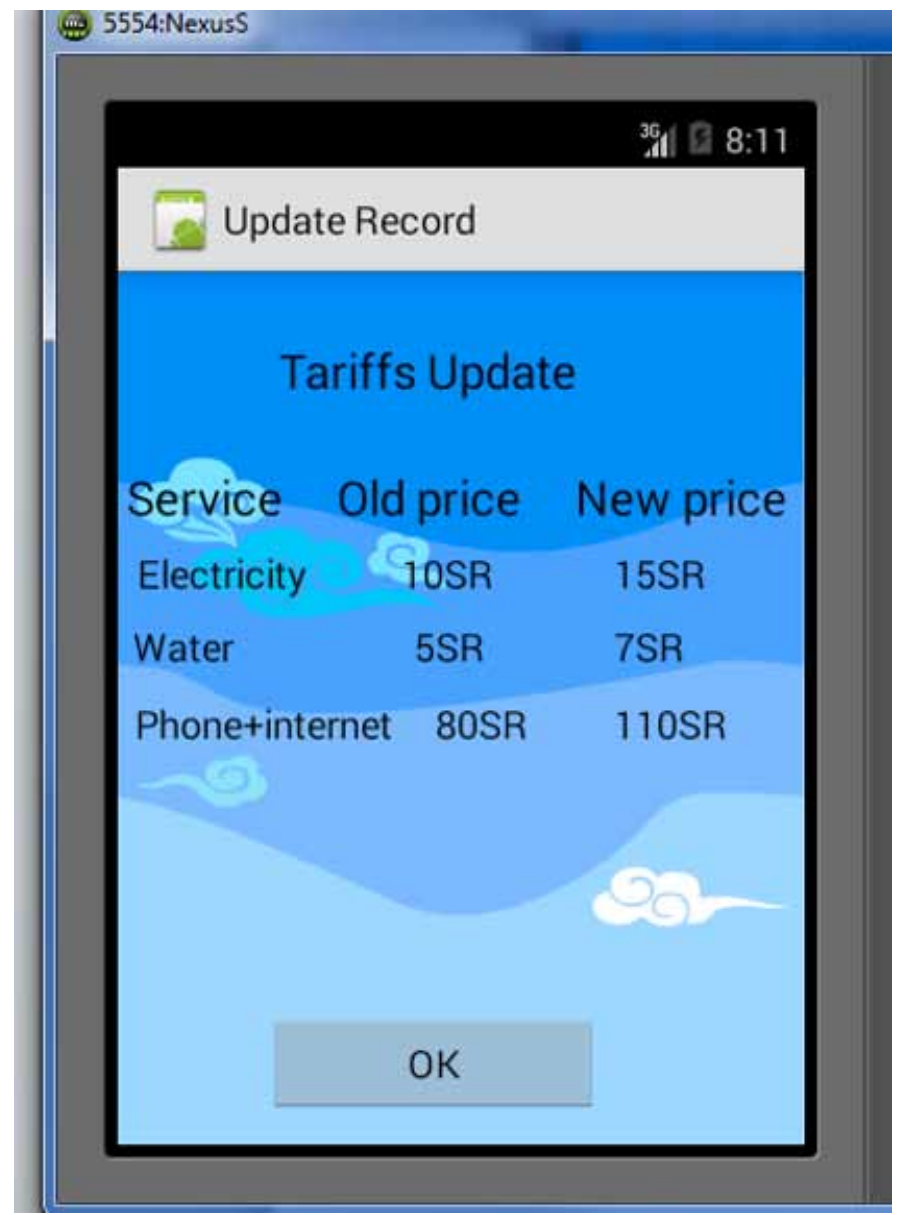

The findings and their interpretation are evaluated relevant to the mobile utility bills payment application using paper sketched prototype (Mianji, Ustringe, 2017). An analysis of the responses gathered from the 41 respondents from Saudi Arabia is given belowfollowed by discussion of the results.

\section{MAIN STUDY}

\section{Demographics Data}

In total, the number of participants who took part on the study was 41, including both males (66\%) and females (34\%) (see Figure 12).

All participants were Saudi citizens specifically selected for this study, aged from 18-49 years (see Figure 13).

Further, majority of the participants belonged to the level of higher education as presented in the graph shown in Figure 14.

Respondents targeted were belonged to the employment segment and that is why they use mobile app (see Figure 15).

$64 \%$ of the participants use iPhone while $36 \%$ use Android (see Figure 16). 
Figure 6.

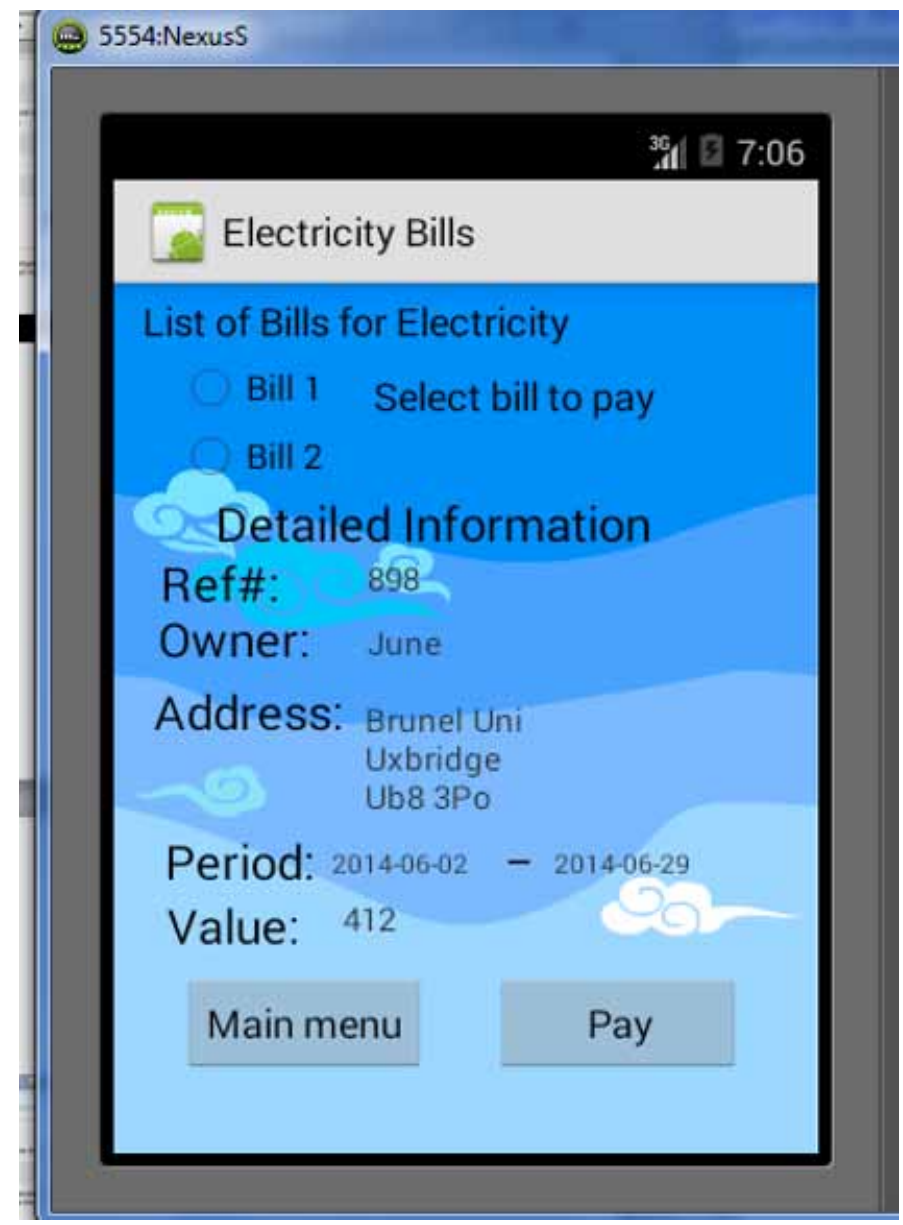

\section{Procedure}

After performing the task in which participants' behaviours were comprehensively observed, these participants were interviewed face-to-face in person through Skype. In order to get feedback on their opinions, open-ended questions were used. All these participants were users of either iPhone or Android.

\section{Findings of Main Study}

About $99 \%$ of the participants were of the opinion that usage of the application was really easy, simple and direct. The applications' simplicity, user-friendly approach and step-by-step guidance were highly appreciated. Participants were of the opinion that the application is an effective tool to help users pay utility bills and also keep track of them. Accordingto participants, the sequential transition of the application from one step to another was very easy and smooth, but they felt that the application was slow, as going back to the previous window brought the user to the initial phase of questioning they had previously answered, which is considered time-consuming.

About $92 \%$ of users are of the opinion that finding information is very easy and simple. Transactions were available according to the participants' previous records and history of payment, which makes record-keeping and tracking payments easy. As participants are provided with various 
Figure 7.

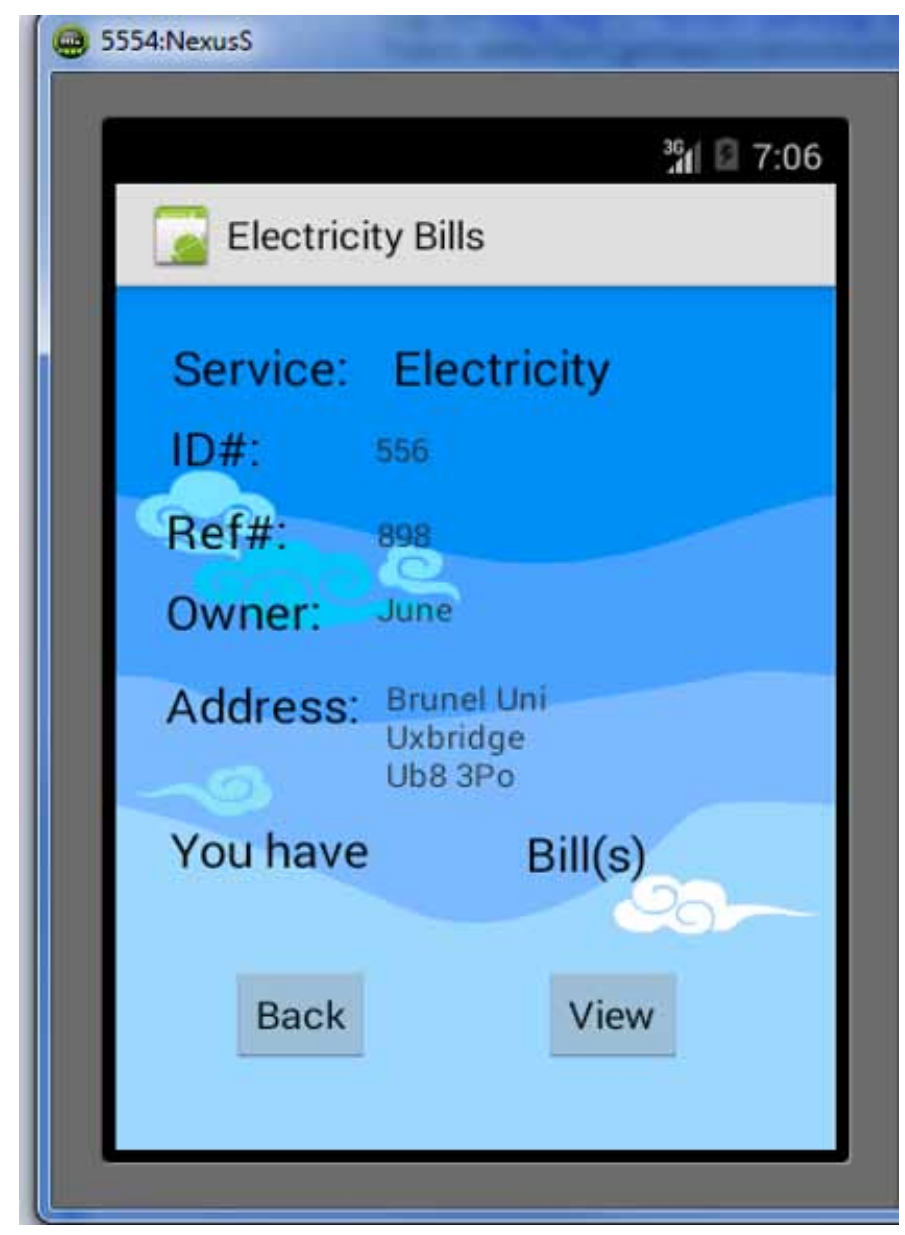

internet packages with different internet packages, updating them about current tariff rates is very helpful and highly appreciated among the users. The availability of different utility providers under one application lessened the hassle of bill payers, hence having a positive impact; $99 \%$ of the participants showed a positive attitude towards the use of service again and they supported the use of this application for all government agencies to pay bills as it is easy and more convenient than traditional methods.

It was anticipated that risk-averse users would be hesitant to disclose financial information due to the uncertainty avoidance associated with traditional cultures in developing countries, so participants were asked to indicate the level of trust they placed in the system regarding the provision of payment-related details. About $70 \%$ of the participants were willing to provide financial details if the service is provided through some trusted government agency or company with a strong security program. Certification of application was highly recommended and in demand to build users' trust and confidence. Some participants had already tested these types of services and disclosed real financial details to service providers, so they consider it a safe and reliable payment method, with no security problems. Moreover, the majority of participants were interested in knowing the security plans and measures that would be taken by the services provided in order to keep their financial details secure and save. Payment through companies like PayPal or VeriSign secured payments are trusted by the participants. 
Figure 8.

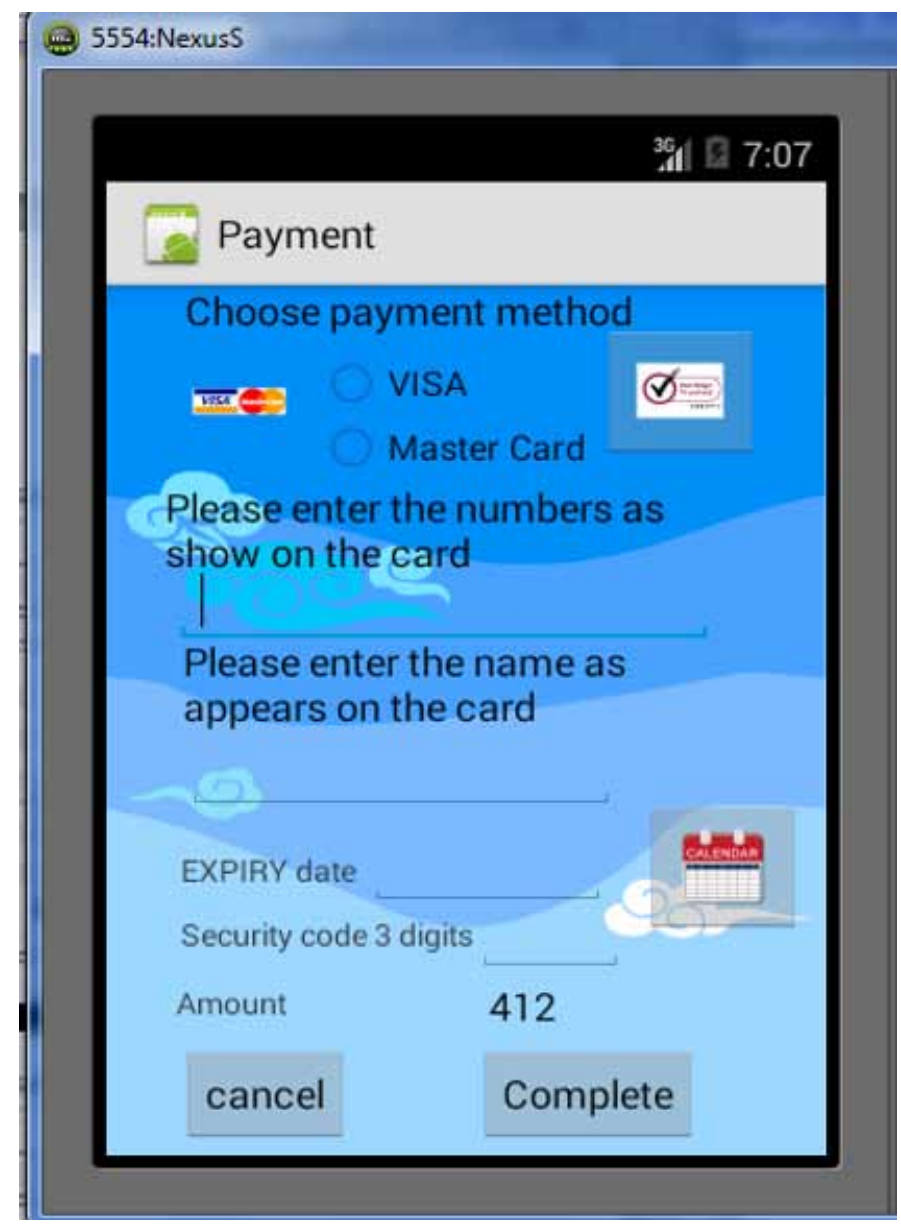

$70 \%$ of the participants were of the view that as long as government official agencies are involved their personal information will remain protected. In Saudi Arabia the government has laws and legislation designed to protect users' data and information. Participants demanded that service providers assure their clients by providing a clear disclaimer. Participants fully trusted the authenticity of the Ministry of Communication and Information Technology in supporting data security, but 20\% of the respondents were not sure about whether their information was protected from unsafe hands. These respondents said that all these security concerns depend on the type of service provider used. Participants were of the view that after using the application one can clearly give feedback and share their true experience. $10 \%$ of the participants were clearly of the opinion that their personal information would be misused and they had insurmountable security concerns while using these applications.

97.6\% of the participants were of the opinion that government must introduce laws and regulation to regulate electronic and mobile transfer data among the stakeholders. It was considered as initial milestone in order to build in peoples trust and encourage the usage of the service. This step would increase the privacy of the information which is considered essential when financial data is involved. This precaution will help Saudi government provide protection to users and save their existing data. Moreover, services controlled by governmental laws and regulation would help avoid tricky legal situations in future that might affect the credibility of service providers. 
Figure 9.

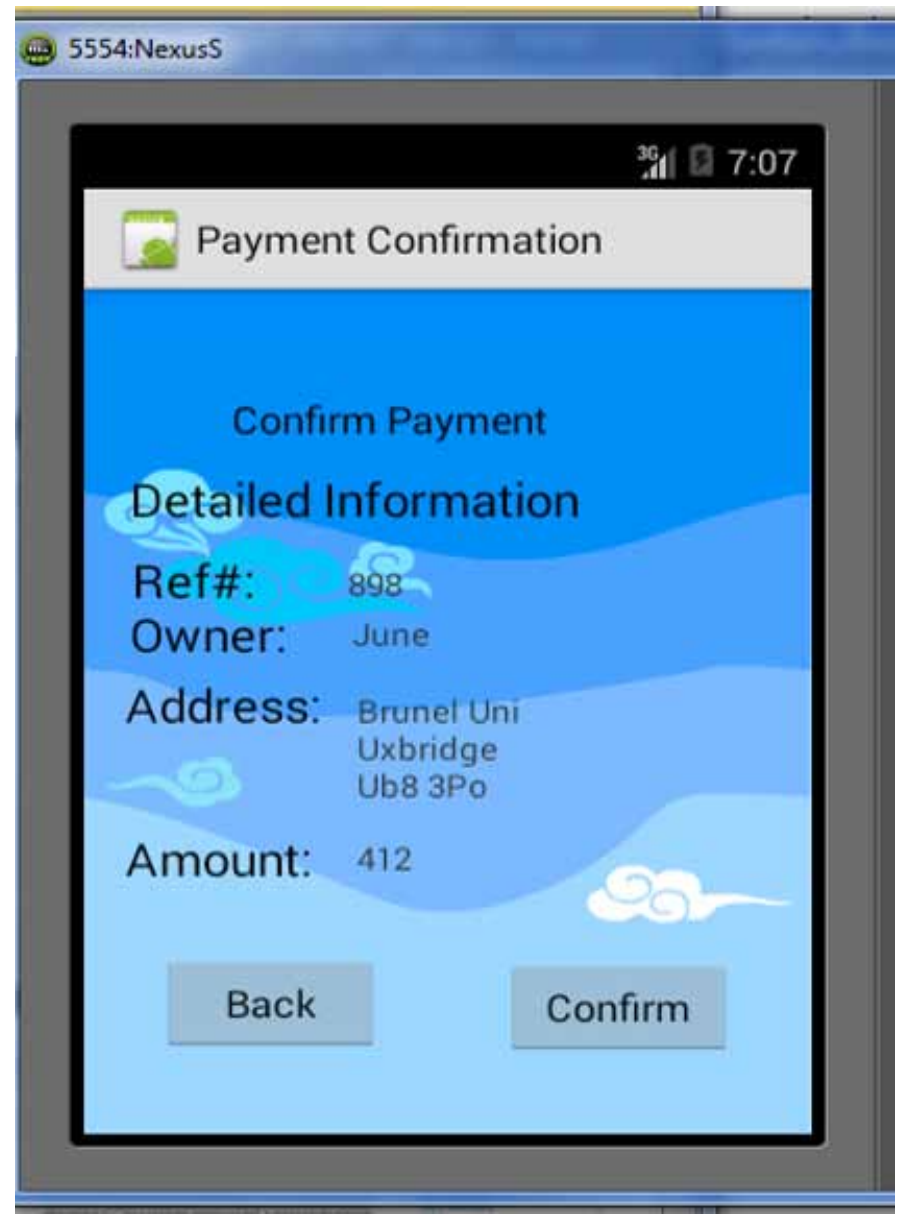

Participants stated that this service is cost-effective in terms of saving time and money. The initial download is free on smart phone, plus it minimizes the physical effort of paying utility bills. Different utilities are combined under one application which reduces the time that would otherwise have been required to pay the bills. Some participants stated the ease with which users find all their billing history with new tariff rates. In short, the application's user-friendly approach, layout, collective data and cost-effectiveness were the main attributes of the services that were highly regarded by the participants.

$76 \%$ of the respondents were already using E-government service. The majority of these respondents used this service to pay fees for the renewal of driving licenses and passports, tariffs and utility bills. ABSHER service (provided by the Ministry of Interior) was commonly used by the participants. This service is considered easy to use, however its access though smart phones and gadgets is slow so participants are required to use laptops. Participants suggested that service should be readily available on smartphones, and it needs to be well structured and secured to attract the audience and increase its usage. 
Figure 10.

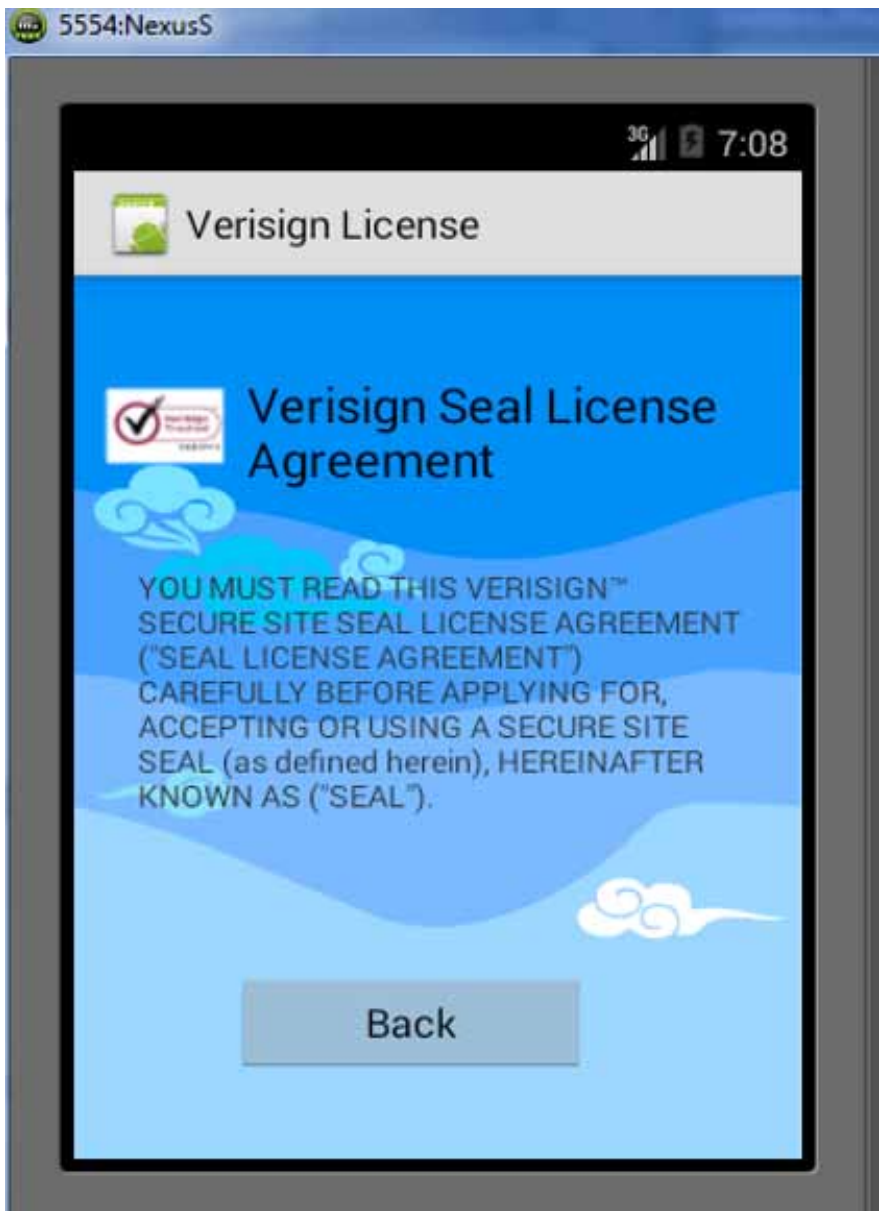

\section{DISCUSSION}

The results of the study focus on the practicality of a mobile phone application for certain government services encompassing the usability, reliability and validity of the service. Understanding of the application attributes and its usage was an imperative component of the research. Also, the current findings can be squared with the existing literature.

Saudi Arabia one of the largest oil producers that, along with the other nations of the GCC, is intensely focused on economic diversification by attempting to build a knowledge economy. This necessitates the development of an IT-based economic system that will have aptitude and maturity for E-commerce applications and techniques. Saudi Arabia is known to have the largest potential market for the growth of information and communications technology. According to one of the surveys conducted by the CITC in Riyadh, in 2012 mobile penetration in Saudi Arabia had reached to $132 \%$. The Telecom Agency of Saudi reports that in 2011 mobile subscribers reached to 54.8\% of the population. Moreover, strong enablers like Facebook, YouTube and Google+ have accomplished maximum growth with a blend of internet, mobile service and social media platform provision in Saudi Arabia. The huge online market in the country is led by Google products marketed in a country-specific way, including YouTube, Google Maps, GPRS and numerous mobile applications. However, existing literature suggest that to encourage and provide easy and secure online facilities in 
Figure 11.

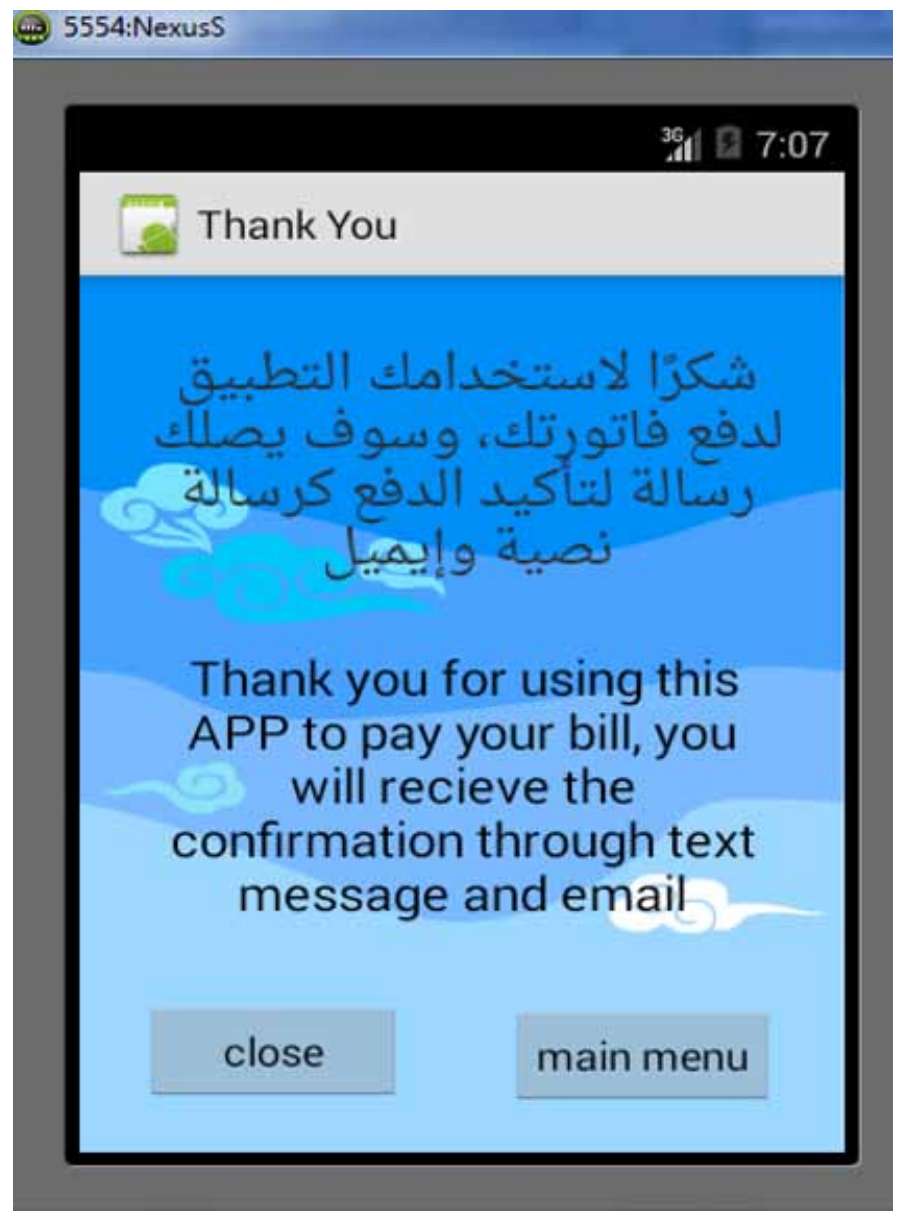

Saudi Arabia, there is need for improvement in key factor of E-commerce activity regarding online payment and transactions. This will help Saudi Arabia to expand internationally and cover global markets successfully as well. Although healthy E-government can develop in Saudi Arabia, it requires professional expertise for ICT tools and overall consensus and acceptance from the organizations and consumers to have proper conduct and competitive prices similar to that available in the market. Many incentives and strategies have been introduced in the Saudi market to encourage organizations to adapt to the online business code of conduct and policies introduced worldwide. However, this can be effectively achieved by support of government in development and expansion of strong IT infrastructure.

There is need for change to implement strategies and facilities that support technologies by use of professional technologies that are efficient for portals and websites and contain whole E-commerce cycle. There is need for better training and education for the workforce in the organization to provide effective customer service and incentives to customers that are currently lacking. Development of employees is very important for continuous improvement and development. Any business has a responsibility to provide secure and efficient payment methods. The Saudi government should consider shifting to E-government ventures more rapidly to enable them to take advantage of customer behaviours in order to pioneer M-government and (by extension) to reduce the barriers to E-commerce in the country. The existing market gap can be converted into market opportunities 


\section{Figure 12.}

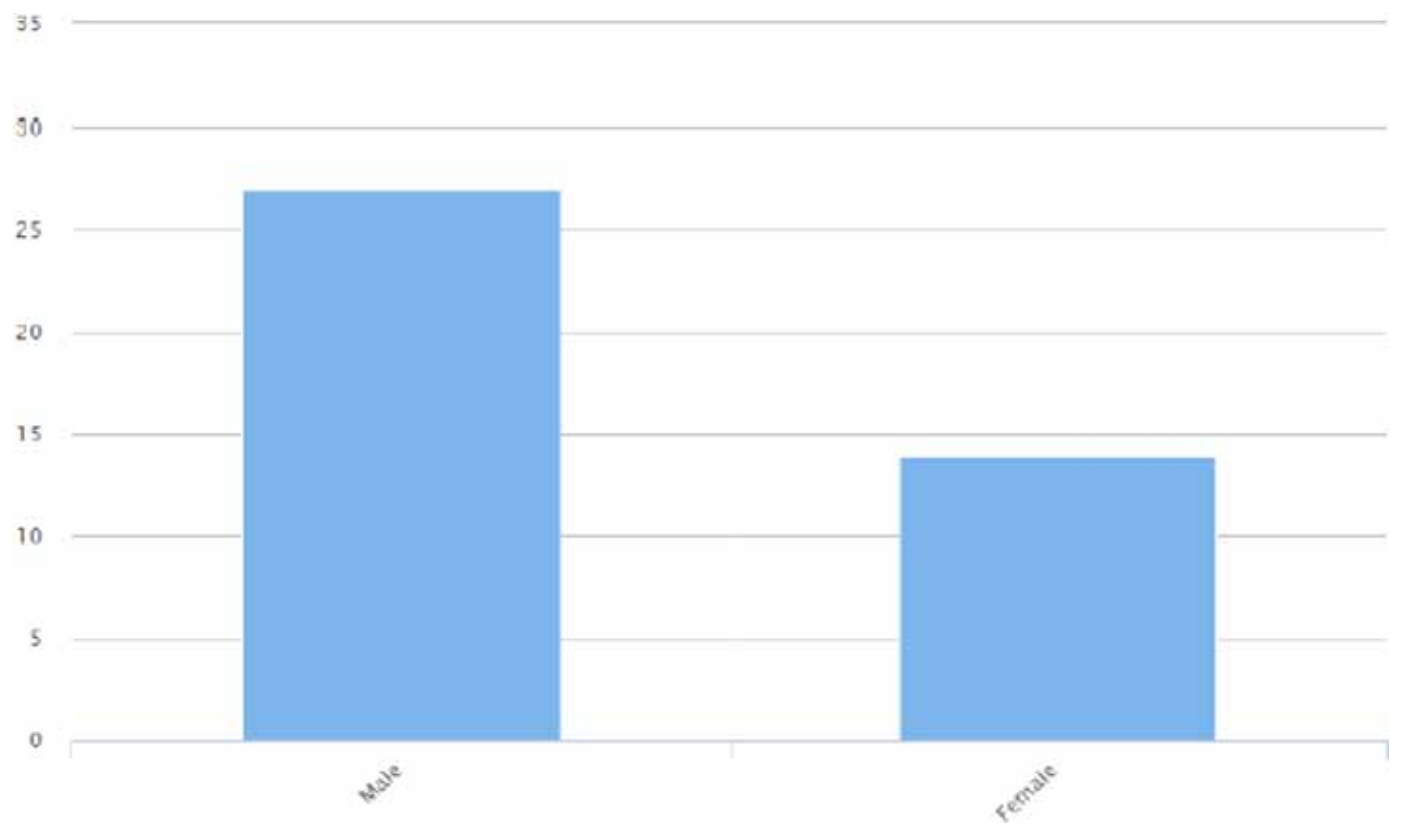

that will later contribute to the overall economic development of the country and lead to job creation and new offerings in form of new business models. In the modern world, the success of electronic services is required by all stakeholders. E-government through mobile service provision helps to regenerate existing business models, diversifying and bringing management changes throughout the organizations. It also reduces the barrier between the government and the citizen, improving transparency and efficiency of governance.

The current findings are supported by the existing literature. As the usage of mobile and different services has increased over time, consumers are willing to try and use new services. The majority of respondents were satisfied with the service usage; the majority of respondents positively agreed

Figure 13.

Responses

$18-25$ yeasr

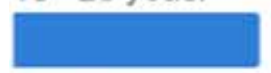

$26-33$ years

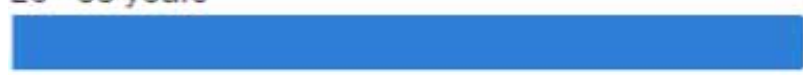

$34-41$ years

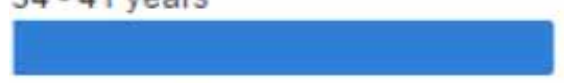

42 - 49 years

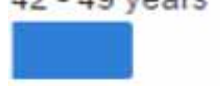

$50+$ years 
Figure 14.

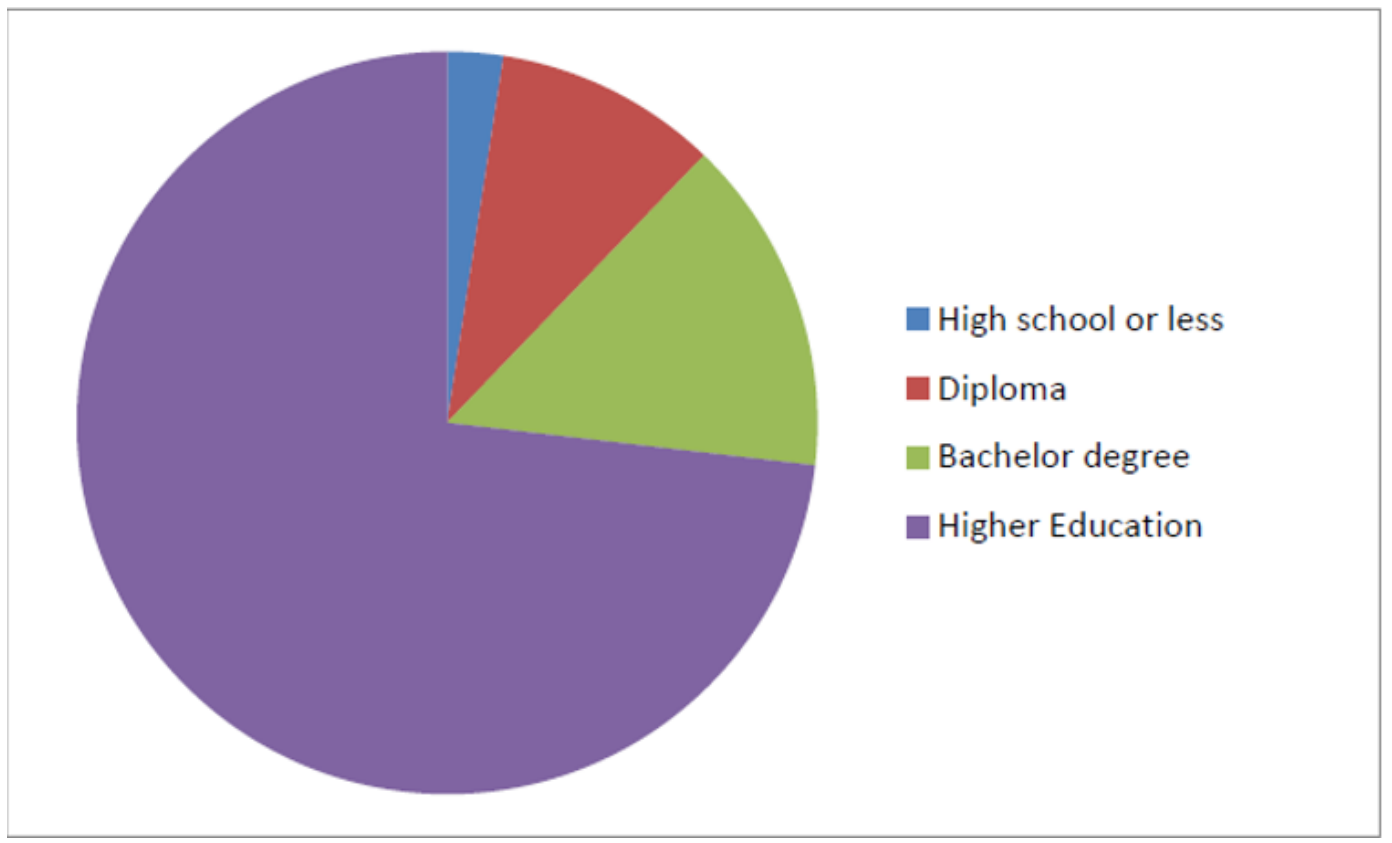

that the application was user-friendly, though the service they used was only a prototype. The service was appreciated most of all for its simplicity and user-friendliness, although ease of use is clearly the main consumer priority, and participants complained about having to renter information if they went back. Bilingual provision was considered simple and easy to understand in both Arabic and English.

Figure 15.

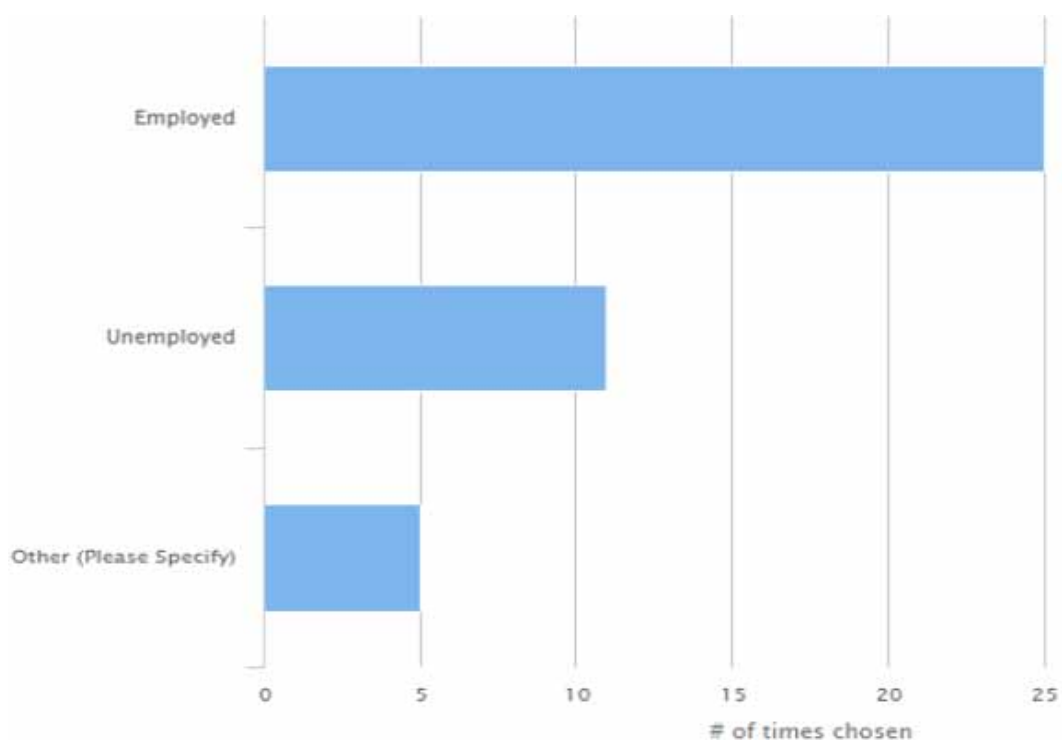




\section{Figure 16.}

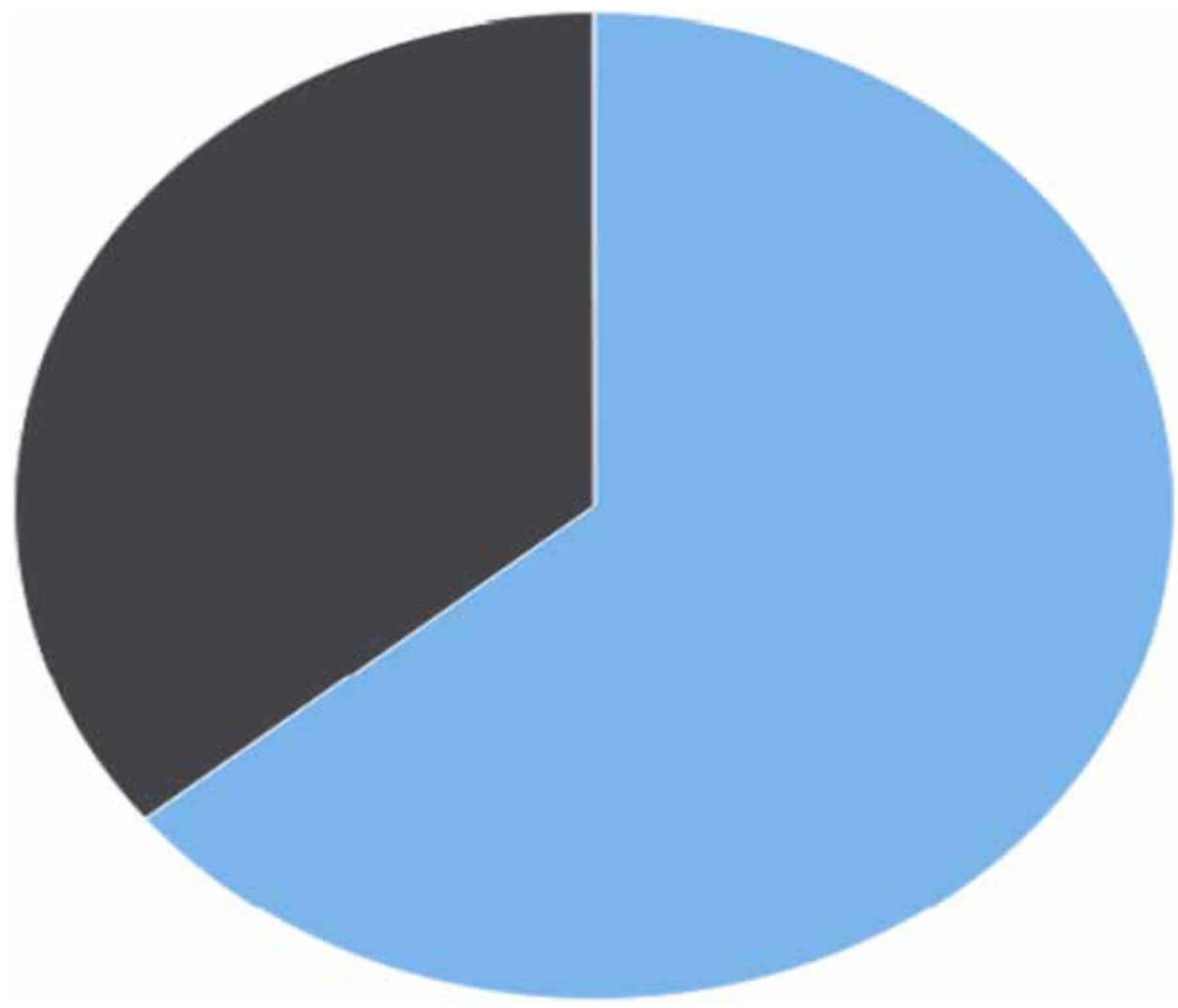

The study suggested that participants' previous record and history of payment transaction being made available helped users with record-keeping and tracking payment easily. The service provided participants with information of various internet packages with different internet packages, which helped them to keep posted with current tariff rates while making payments, which is very helpful and highly appreciated among users. Different utilities are combined under one application, which reduces the time that would otherwise have been required to pay the bills. It is clear from the findings and existing literature also supports the facts that participants were concerned about security and safety of information. Participants were not comfortable to leave their details pertaining to credit card or any personal information. Misuse of information was major threat to participants which further added reluctance to usage of the application.

Respondents were willing to provide financial details if service is provided through some trusted company of the government agencies with best security program. Certification of application was highly recommended and in demand to build in users trust and confidence. Moreover, these users were interested in knowing the security plans and measures that would be taken by the services provided in order to keep their financial details secure and save. Payment through companies like PayPal or VeriSign secured payments are trusted by the participants. Participants trusted government agencies and recommended the support of the Ministry of Communication and Information Technology in data security. 


\section{CONCLUSION}

The study emphasized finding if the mobile users in Saudi Arabia perceived the use of mobile internet applications useful or not. The study also focused on revealing to participants that whatever activities they performed in a traditional way of paying utilities bills is also possible by use of mobile phone in fewer steps. In order to serve this purpose, mobile service was developed that dealt with important aspects of billing-related activities with respect to Saudi Arabia.

It was clear in the study that application usage is considered easy, user-friendly and convenient. The application was considered cost-effective in terms of time and money. One application containing different utility departments with information of different tariff rates made it more attractive in eye of the participants. However, the issue of trust and security was repeatedly highlighted by the participants. As the result, many of the participants were reluctant to use such services in near future as financial and personal information is involved. These participants are following uncertainty avoidance in a very direct matter.

The results of the different studies helped to do better analysis. The first study focused on the usage and validity of mobile government service to pay bills in Saudi Arabia, while the second analysed an existing M-government service already operational in the country. This comparison helped understand the usability and familiarity issue that might arise with new upcoming services. It also helped in better understanding of Saudi Arabia in terms of its internet and mobile market.

The findings of this study would help the relevant departments to develop and implement M-government services to facilitate governance (i.e. the service of citizens) in the country. This study offers lessons for governments in developing countries willing to provide services through mobiles. 


\section{REFERENCES}

Ahmad, S. Z., \& Khalid, K. (2017). The adoption of M-government services from the user's perspectives: Empirical evidence from the United Arab Emirates. International Journal of Information Management, 37(5), 367-379.

Al-Khatib, H., Lee, H., Suh, C. \& Weerakkody, V. (2019). E-government systems success and user acceptance in developing countries: The role of perceived support quality. Academic Press.

Albugami, S. \& Ahmed, V. (2015). Success factors for ICT implementation in Saudi secondary schools: From the perspective of ICT directors, head teachers, teachers and students. International Journal of Education and Development using ICT, 11(1).

Alenezi, H., Tarhini, A. \& Masa'deh, R. (2015). Investigating the strategic relationship between information quality and e-government benefits: A literature review. Academic Press.

Ali, K. E., Mazen, S. A., \& Hassanein, E. E. (2018). A proposed hybrid model for adopting cloud computing in e-government. Future Computing and Informatics Journal, 3(2), 286-295.

Almaimoni, H., Altuwaijri, N., Asiry, F., Aldossary, S., Alsmadi, M., Al-Marashdeh, I., Badawi, U. A., Alshabanah, M., \& Alrajhi, D. (2018). Developing and Implementing WEB-based Online Destination Information Management System for Tourism. International Journal of Applied Engineering Research, 13(10), 7541-7550.

Alonazi, M., Beloff, N., \& White, M. 2019, June. Developing a model and validating an instrument for measuring the adoption and utilisation of mobile government services adoption in Saudi Arabia. In Federated Conference on Computer Science and Information Systems. Institute of Electrical and Electronics Engineers.

Alotaibi, S., \& Roussinov, D. 2015, June. A conceptual model for examining mobile government adoption in Saudi Arabia. In European Conference on e-Government (p. 369). Academic Conferences International Limited.

Alrowili, T. F., Alotaibi, M. B., \& Alharbi, M. S. 2015, April. Predicting citizens' acceptance of M-government services in Saudi Arabia an empirical investigation. In 2015 Annual IEEE Systems Conference (SysCon) Proceedings (pp. 627-633). IEEE.

Arias, M. I., \& Maçada, A. C. G. 2018, April. Digital Government for E-Government Service Quality: a Literature Review. In Proceedings of the 11th International Conference on Theory and Practice of Electronic Governance (pp. 7-17). ACM.

Baabdullah, A. M., Alalwan, A. A., \& Al Qadi, N. S. 2018. Evaluating the Current Situation of Mobile Services (M-Services) in the Kingdom of Saudi Arabia. In Emerging Markets from a Multidisciplinary Perspective (pp. 149-160). Springer.

Börnert, M., \& Wilbert, J. (2015). Thinking-aloud protocols of Piagetian tasks: Insights into problem-solving processes of primary school students. Insights into Learning Disabilities, 12(1), 19-34.

Ciesielska, M., \& Janowski, T. (2019, September). Inter-governmental Collaborative Networks for Digital Government Innovation Transfer-Structure, Membership, Operations. In Working Conference on Virtual Enterprises (pp. 295-307). Springer.

Cleveland, M., Rojas-Méndez, J. I., Laroche, M., \& Papadopoulos, N. (2016). Identity, culture, dispositions and behavior: A cross-national examination of globalization and culture change. Journal of Business Research, 69(3), 1090-1102.

Cowan, N. (2017). The many faces of working memory and short-term storage. Psychonomic Bulletin \& Review, 24(4), 1158-1170. PMID:27896630

Davis, N., Hsiao, C. P., Popova, Y., \& Magerko, B. (2015). An enactive model of creativity for computational collaboration and co-creation. In Creativity in the Digital Age (pp. 109-133). Springer.

Dereli, D. D. (2015). Innovation management in global competition and competitive advantage. Procedia: Social and Behavioral Sciences, 195, 1365-1370.

Franklin, U. E., \& Aguenza, B. B. (2016). Obstacles, resistance and impact of change in organizations: An examination of the Saudi telecommunication company (STC). International Journal of Academic Research in Business and Social Sciences, 6(4), 23-37. 
Isagah, T., \& Wimmer, M. A. 2017, March. Mobile government applications: Challenges and needs for a comprehensive design approach. In Proceedings of the 10th International Conference on Theory and Practice of Electronic Governance (pp. 423-432). ACM.

Jasimuddin, S. M., Mishra, N., Saif, A., \& Almuraqab, N. (2017). Modelling the factors that influence the acceptance of digital technologies in e-government services in the UAE: A PLS-SEM Approach. Production Planning and Control, 28(16), 1307-1317.

Joshi, P., Islam, S., \& Islam, S. (2017). A framework for cloud based E-government from the perspective of developing countries. Future Internet, 9(4), 80.

Kanaan, R.K., Abumatar, G., Al-Lozi, M. \& Hussein, A.M.A. (2019). Implementation of M-government: Leveraging Mobile Technology to Streamline the E-governance Framework. Journal of Social Sciences, 8(3), 495-508.

Kelly, M., Dowling, M., \& Millar, M. (2018). The search for understanding: The role of paradigms. Nurse Researcher, 25(4), 9-13. PMID:29546961

Khazma, J., Al-Najjar, D. K., \& Steinberg, D. H. (2016). Customer service \& Hofstede's cultural dimensions in Lebanon, the Kingdom of Saudi Arabia, \& the USA among entrepreneurial finance professionals. Allied Academies International Conference. Academy of Entrepreneurship Proceedings, 22(1), 21.

Kumar, V. (2017). The think aloud method: Some concerns addressed. Journal of Modern Languages, 15(1), $13-25$.

Lallmahomed, M. Z., Lallmahomed, N., \& Lallmahomed, G. M. (2017). Factors influencing the adoption of e-Government services in Mauritius. Telematics and Informatics, 34(4), 57-72.

Liu, N., \& Ma, L. 2019, July. Challenges and Opportunities of E-government in Big Data Era. In 2019 4th International Conference on Humanities Science and Society Development (ICHSSD 2019). Atlantis Press. doi:10.2991/ichssd-19.2019.19

López-López, V., Iglesias-Antelo, S., Vázquez-Sanmartín, A., Connolly, R., \& Bannister, F. (2018). e-Government, Transparency \& Reputation: An Empirical Study of Spanish Local Government. Information Systems Management, 35(4), 276-293.

Mahmood, M. (2019). Transformation of Government and Citizen Trust in Government: A Conceptual Model. In Strategic Management and Innovative Applications of E-Government (pp. 107-122). IGI Global.

Mainka, A., Hartmann, S., Meschede, C. \& Stock, W.G. (2015). Mobile application services based upon open urban government data. iConference 2015 Proceedings.

Mianji, M., \& Ustringer, L. L. C. (2017). Method And Apparatus For Communication Using Images, Sketching, And Stamping. U.S. Patent Application 15/649,559.

Morente-Molinera, J. A., Pérez, I. J., Ureña, M. R., \& Herrera-Viedma, E. (2015). On multi-granular fuzzy linguistic modeling in group decision making problems: A systematic review and future trends. KnowledgeBased Systems, 74, 49-60.

Nawafleh, S. (2018). Factors affecting the continued use of e-government websites by citizens: An exploratory study in the Jordanian public sector. Transforming Government: People. Process and Policy, 12(3/4), 244-264.

Oreg, S., \& Sverdlik, N. (2018). Translating Dispositional Resistance to Change to the Culture Level: Developing a Cultural Framework of Change Orientations. European Journal of Personality, 32(4), 327-352.

Palas, M.J.U., Uddin, R. \& Hassan, M. (2019). Digitising government payments in Bangladesh: a mobile banking approach. Electronic Government, an International Journal, 15(2), 166-188.

Pradhan, P., \& Shakya, S. (2018). Big Data Challenges for e-Government Services in Nepal. Journal of the Institute of Engineering, 14(1), 216-222.

Robertson, C. J., Al-Khatib, J., \& Rasheed, M. F. (2013). A cross-national analysis of corporate citizenship: Saudi Arabia vs. the United States. Journal of Managerial Issues, 284-298. 
Santa, R., MacDonald, J. B., \& Ferrer, M. (2019). The role of trust in e-Government effectiveness, operational effectiveness and user satisfaction: Lessons from Saudi Arabia in e-G2B. Government Information Quarterly, 36(1), 39-50.

Saunders, M.N., Lewis, P., Thornhill, A. \& Bristow, A. (2015). Understanding research philosophy and approaches to theory development. Academic Press.

Saxena, S. (2017). Enhancing ICT infrastructure in public services: Factors influencing mobile government (m-government) adoption in India. The Bottom Line (New York, N.Y.), 30(4), 279-296.

Scott-Jackson, W., \& Michie, J. (2017). Culture and Business Operations: How the Gulf Arab Leadership Style Impacts a Contingent Human Resource Management. In Business and Society in the Middle East (pp. 31-47). Palgrave Macmillan.

Sultana, M. R., Ahlan, A. R., \& Habibullah, M. D. (2016). A comprehensive adoption model of m-government services among citizens in developing countries. Journal of Theoretical \& Applied Information Technology, 90(1).

Thompson, N., Mullins, A., \& Chongsutakawewong, T. (2019). Does high e-government adoption assure stronger security? Results from a cross-country analysis of Australia and Thailand. Government Information Quarterly, 101408.

Valle-Cruz, D. (2019). Public value of e-government services through emerging technologies. International Journal of Public Sector Management.

Wallace, M., \& Sheldon, N. (2015). Business research ethics: Participant observer perspectives. Journal of Business Ethics, 128(2), 267-277.

Walliman, N. (2017). Research methods: The basics. Routledge. 
International Journal of Operations Research and Information Systems

Volume $12 \cdot$ Issue $2 \cdot$ April-June 2021

\section{APPENDIX}

Figure 17.

$\bullet \bullet \bullet \circ$ vodafone UK ₹ 06:48

$80 \% \square$

\section{< Welcome Login or Register}

\section{Please login or register your}

detials to use the application

\section{Login}

Register 
Figure 18.

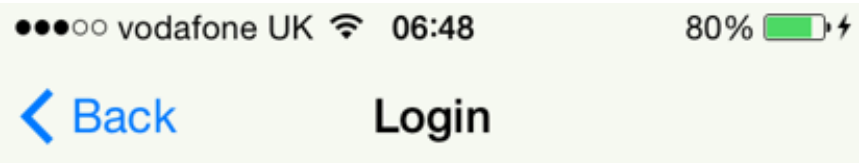

\section{Enter UserName and Password to Sign In}

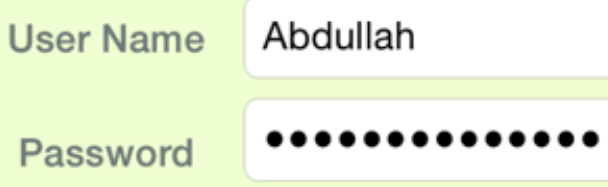

Sign In

Forgot Password?

Not Registered? 
Figure 19.

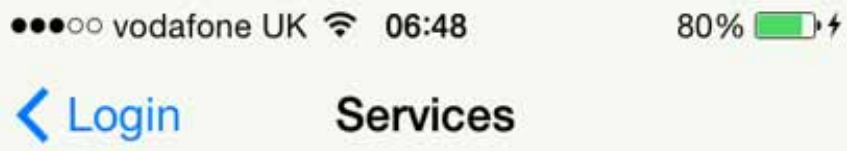

Please Select your services or check new tariffs

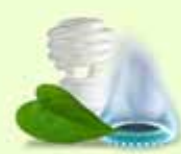

\section{Tariff Update}
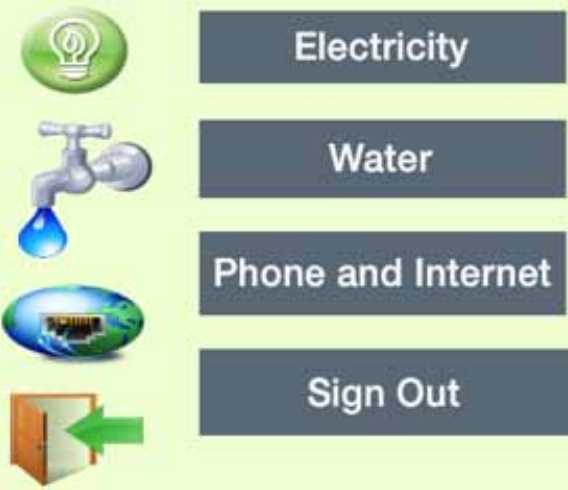

Phone and Internet

Sign Out 
Figure 20.
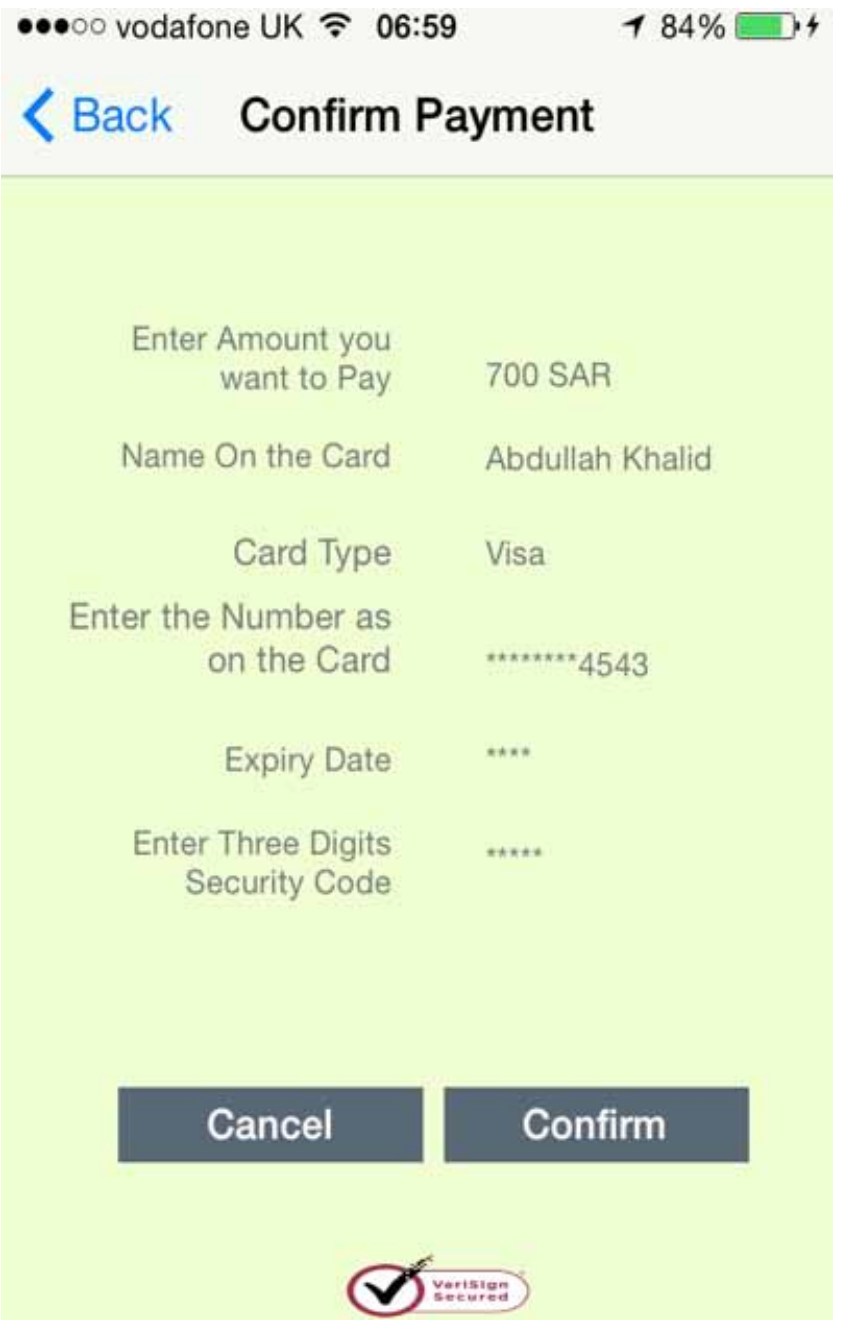
Figure 21.
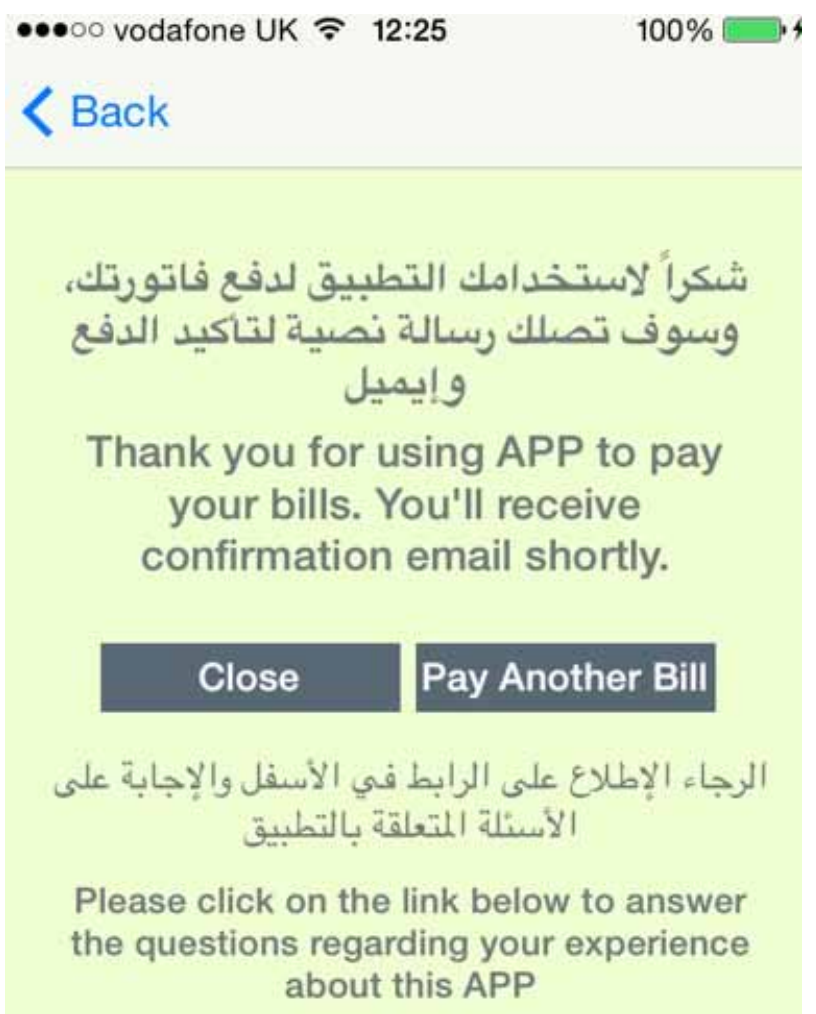

\section{Link to Survey}

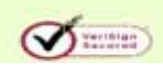

Steve Love heads research activities in the School of Simulation and Visualisation at The Glasgow School of Art. His primary research expertise is investigating the impact of digital applications and services on people's behaviour and lives. He has been the Principle Investigator, Project Originator, Project Lead and Project Partner on research projects that have been sponsored by funders such as the AHRC, EPSRC, InnovateUK, Scottish Funding Council, European Space Agency, the European Social Fund, BT, Orange, Sharp Laboratories Europe and "3". He is a member of the Arts and Humanities Research Council's Peer Review College and a Fellow of the Design Research Society. 